\title{
Gene expression signature of parathion-transformed human breast epithelial cells
}

\author{
GLORIA M. CALAF ${ }^{1-3}$ and DEBASISH ROY ${ }^{4}$ \\ ${ }^{1}$ Institute for Advanced Research and ${ }^{2}$ Center for the Man in the Desert, Tarapaca University, Arica, Chile; \\ ${ }^{3}$ Center for Radiological Research, Columbia University Medical Center, New York, NY; \\ ${ }^{4}$ Department of Natural Sciences, HCC, The City University of New York, NY, USA
}

Received November 23, 2006; Accepted December 30, 2006

\begin{abstract}
Environmental substances seem to be involved in the etiology of breast cancers. Many studies have found an association between human cancer and exposure to agricultural pesticides such as the organophosphorous pesticides. Parathion is a cholinesterase inhibitor that induces the hydrolysis of body choline esters, including acetylcholine at cholinergic synapses. The primary target of action in insects is the nervous system whereby pesticides inhibit the release of the enzyme acetylcholinesterase at the synaptic junction. Atropine is a parasympatholytic alkaloid used as an antidote to acetylcholinesterase inhibitors. The aim of this study was to determine the effect of parathion and atropine on cell transformation of human breast epithelial cells in vitro. These studies showed that parathion alone was able to induce malignant transformation of an immortalized human breast epithelial cell line, MCF-10F as indicated by increased cell proliferation, anchorage independency and invasive capabilities. There was also an increase in c-kit, Trio, Rho-A, Rac-3, EGFR, Notch-4, Dvl-2, Ezrin, B catenin and mutant p53 protein expression in the parathion-treated cells. However, atropine significantly inhibited this increase. In a human cell cycle array of 96 genes, 13 of them were altered by parathion treatment. Among the genes affected were the cyclins, such as cyclin D3, the cyclin-dependent kinases (CDKs) such as CDK41 and the minichromosome maintenance deficient (MCM) MCM2 and MCM3. It is suggested that parathion influences human breast epithelial cell transformation and is an initiator factor in the transformation process in breast cancer.
\end{abstract}

Correspondence to: Dr Gloria M. Calaf, Columbia University Medical Center, Center for Radiological Research, VC11-218, 630 West 168th Street, New York, NY 10032, USA

E-mail: gmc24@columbia.edu

Key words: organophosphorous pesticides, parathion, malignant transformation of breast epithelial cells

\section{Introduction}

Breast cancer is the most common neoplasm that affects women worldwide with approximately 1 in 11 developing the malignancy and 1 in 30 dying from the disease $(1,2)$. Organophosphorous compounds are the most widely used pesticides by virtue of their biodegradable nature and short persistence. These compounds not only produce biological and pathological changes but also cause significant biochemical alterations. Organophosphorous compounds have been used in medicine for various treatments, such as miastenia gravis, glaucoma, vesical atony, cancer treatment (3) and Alzheimer's disease (4). In the chemical industries, these compounds have been used as additives in oil dissolvents in the dye industry and in artificial leather. Parathion, in particular, is used to control mosquitoes and insect plagues. It is also present in lotions and shampoos marketed for the treatment of head lice and mites for use by human beings (5).

The organophosphorous pesticide parathion [O,O-diethyl O-(4-nitrophenyl)-phosphorothioate)] is involved in the inhibition of acetylcholinesterase with a subsequent impairment of normal nervous function at cholinergic synapses $(6,7)$. The inhibition of this enzyme consequently leads to excessive acetylcholine accumulation at the synapses and neuromuscular junctions, which ultimately results in the overstimulation of acetylcholine receptors. Atropine is a parasympatholytic alkaloid used as an antidote to acetylcholinesterase inhibitors and acts through competitive occupation of muscarinic cholinergic receptors (7). Parathion, an organophosphorous pesticide is not an established human carcinogen but we recently reported that this substance induced mammary tumors after subcutaneous injection in the rat (8). Atropine, on the other hand, inhibited the effect of this substance and did not induce tumors.

The development of tumor initiation appears to involve increase in cell division as well as increase in risks of genetic damage that induce activation and/or changes in the expression of oncogenes and the loss or inactivation of tumor suppressor genes (9-11). Thus, transformation of breast cells leads to regulation of signal transduction pathways, abnormal amplification of growth signals, and aberrant expression of genes that ultimately transform the cells into invasive cancer. The complex series of cellular and molecular changes that 
occur through the development of cancers can be mediated by a diversity of endogenous and environmental stimuli. Specific abnormalities convert normal cells to latent tumor cells by altering genetic material. Therefore, knowledge of these specific genetic changes is critical to an understanding of the disease. Transformed cells can be identified by both morphological and molecular changes, e.g. lack of anchorage independency, invasive characteristics and differentially expressed genes (12-16).

Several genes selected in this study were taken into consideration due to the altered differential expression observed in the cDNA arrays performed previously with transformed cells (12). Among them c-kit, Trio, Rho-A, Rac-3, epidermal growth factor receptor (EGFR), Notch-4, Disheveled homolog (Dvl-2), Ezrin (villin 2), $\beta$ catenin and mutant p53 were up-regulated in comparison to the control cell line. Proliferative signaling pathways often begin with the activation of a receptor tyrosine kinase by a growth factor, although activation of some G-protein-coupled receptors can also activate certain branches of this signaling pathway. The $c$-kit is a proto-oncogene identified as a member of the receptor tyrosine kinase family. It is closely related to the platelet-derived growth factor receptor and is expressed in breast cancer $(17,18)$.

Trio is a protein tyrosine phosphatase which is membrane-associated or localized in nuclei (19). Trio may exhibit Rac-specific activity or Rho-specific activity. Rac 1 is a GTP-binding protein of the Ras superfamily which regulates many fundamental processes in all eukaryotic cells such as growth, vesicle traffic and cytoskeletal organization (20-22). Depending on the proteins that are subsequently recruited by the activated receptor, several downstream signaling pathways may be activated (23).

EGFR promotes cell proliferation and differentiation and is part of a subfamily of four closely related receptors EGFR (ErbB-1), neu (ErbB-2), Her 3 (ErbB-3) and Her 4 (ErbB-4) (24). HER 2 (ErbB-2, Neu) and HER 3 (ErbB-3) are other members of the EGF receptor family that do not have wellcharacterized ligands $(25,26)$. It is on the surface of cells to which epidermal growth factor (EGF) binds; EGFR is found at abnormally high levels on the surface of many types of cancer cells (27).

The Notch genes are expressed in a variety of tissues suggesting that they are involved in multiple signaling pathways. The LIN-12/Notch family of transmembrane receptors is believed to play a central role in development by regulating cell fate decisions (28). The 280-330-kDa Notch proteins are overexpressed or rearranged in human tumors (29).

The Dvl gene regulates cell proliferation and is a human homolog of the Drosophila Dishevelled gene ( $d s h)$ that encodes a cytoplasmic phosphoprotein acting as a transducer molecule for developmental processes (30). It may be involved in controlled proliferation and migration of vascular endothelial cells. Both dsh and frizzled proteins (Ezrin) are components of the WNT signaling pathways $(31,32)$.

E-cadherin and $B$ catenin are important epithelial adhesion molecules in normal epithelium. The $92-\mathrm{kDa}$ catenin $B$ associates with the cytoplasmic portion of E-cadherin, which is necessary for the function of E-cadherin as an adhesion molecule (33). Loss of E-cadherin - $\beta$ catenin adhesion is an important step in the progression of many epithelial malignancies (34).

The $p 53$ gene has been identified as an important tumor suppressor gene in normal cells and is involved in regulation of the normal cell cycle. When it is inactivated, cells may undergo uncontrolled proliferation $(35,36)$. When mutant $p 53$ fails to mediate any of these effects, the uncontrolled proliferation occurs in the absence of wild-type $p 53$. This effect yields a high level of genomic instability that is a common abnormality detected in primary breast cancer. Thus mutant p53 increases from $13 \%$ to $50 \%$ as breast cancer progresses from early in situ to advanced metastatic lesions $(36,37)$.

The genes essential for DNA damage and mitotic spindle checkpoints, as well as genes in APC ubiquitin-conjugation complexes are represented in a human cell cycle gene array (38-42). It contains genes related to the $\mathrm{S}$ phase such as the cyclins (A1, A2, C, G1, G2, H), CDKs and minichromosome maintenance deficient (MCM). The aim of the present study was to determine whether MCF-10F, a normal breast cell line is altered by the organophosphorous pesticide parathion (parathion-ethyl) as indicated by features of transformation and differentially expressed genes assessed with cDNA arrays of human cell cycle; and whether atropine acts as an antidote for such substances and reduces such effects.

\section{Materials and methods}

Cell lines and treatment. The spontaneously immortalized cell line MCF-10F that arose from a mortal human diploid breast epithelial cell line (43) was used in this study. It shares most of the structural characteristics of a normal epithelium $(13,43-46)$. To determine the effect of pesticides in MCF-10F on cell proliferation, cells were treated with 100, 200, 400 or $800 \mathrm{ng} / \mathrm{ml}$ of parathion. This substance was also analyzed in combination with atropine at doses of $0,62.5,125$ and $250 \mu \mathrm{g} /$ $\mathrm{ml}$. Cell proliferation was determined by using the trypan blue exclusion method. MCF-10F was treated with $100 \mathrm{ng} / \mathrm{ml}$ parathion and $125 \mathrm{ng} / \mathrm{ml}$ atropine during 20 passages before performing the subsequent experiments.

Anchorage-independent and cell invasion assay. To test for cell growth in semi-solid medium, cells in passage 20 after parathion treatment were trypsinized and plated at a density of $2 \times 10^{5}$ cells in $10 \mathrm{ml}$ of $0.35 \%$ agarose over a $0.7 \%$ agar base in 100-mm culture dishes as described $(13,45)$. Media were replenished every other day and colonies with more than 50 cells were scored after 4 weeks in culture. Invasiveness was carried out as described previously $(13,46)$ using modified Boyden's chambers (Transwell; Costar, Cambridge, MA). The inserts were converted into invasion chambers by applying a layer of basement membrane onto the surface of microporous filters in each unit. Briefly, the 8-mm-diameter filters $(8-\mu \mathrm{m}$ pore) of cell culture inserts were coated with $60 \mu \mathrm{g} /$ filter basement membrane of matrigel (Collaborative Research, Bedford, MA) reconstituted with $100 \mu 1$ of MEM with $0.1 \%$ bovine serum albumin (BSA) (Collaborative Research). Such filters were coated and dried overnight. Exponentially growing control and treated cell lines were 
trypsinized, harvested, suspended in DMEM plus horse serum, and $3 \times 10^{4}$ cells/chamber were added to the upper chamber. Fibronectin (Collaborative Research) was used as a chemo-attractant at a concentration of $1 \mu \mathrm{g} /$ chamber in $0.5 \mathrm{ml}$ of MEM with $0.1 \%$ BSA and placed in the lower chamber. The cells on the upper surface of the filter were kept for $20 \mathrm{~h}$ at $37^{\circ} \mathrm{C}$ in $5 \% \mathrm{CO}_{2}$, and after this period cells from the top were removed by wiping with a cotton swab. The total number of cells that crossed the membrane was counted under a light microscope. Experiments were performed three times.

Oncoprotein expression determined by confocal microscopy. Exponentially growing control and treated cells were plated on a glass chamber slide (Nunc Inc., Naperville, IL), as previously described $(13,15)$. Cells plated at a density of $1 \times 10^{4}$ in $1 \mathrm{ml}$ of medium were allowed to grow for 2-3 days. Cells were fixed with buffered paraformaldehyde in PBS ( $\mathrm{pH}$ 7.4), blocked with endogenous peroxidase with $1 \% \mathrm{H}_{2} \mathrm{O}_{2}$ in methanol for $30 \mathrm{~min}$ and incubated with the corresponding primary antibodies at a 1:500 dilution overnight at $4^{\circ} \mathrm{C}$. The c-kit (sc-168) rabbit polyclonal, Trio (sc-6061) rabbit polyclonal, Rho-A (sc-418) mouse, Rac-3 (sc-16698) goat polyclonal, EGFR (sc-03) rabbit polyclonal, Notch-4 (sc8644) goat polyclonal, Dvl-2 (sc-7399) goat polyclonal, Ezrin (sc-6407) goat polyclonal, ß catenin (sc-7963) mouse monoclonal and mutant p53 (Pab240, sc-99) mouse antibodies were used (Biotechnology Inc., Santa Cruz, CA). Cells were incubated for $60 \mathrm{~min}$ at room temperature with anti-mouse rhodamine-conjugated secondary antibody (Jackson ImmunoResearch Lab., West Grove, PA) at a 1:1000 dilution. Slides were mounted with Vectashield mounting media (Vector Laboratories, Burlingame, CA). Controls included cultures stained with either the primary or secondary antibodies alone to monitor the background staining. Cells were viewed and quantified on Zeiss Axiovert $100 \mathrm{TV}$ microscope (Carl Zeiss, Thornwood, NY) using a x40 11.3 NA objective lens equipped with a laser scanning confocal attachment (LSM 410 Carl Zeiss). To excite the rhodamine secondary antibody the fluorescent images were collected by an argon/krypton mixed gas laser (488 nm). Fluorescent images were collected in black and white and changed to green or red color by Photoshop. Composite images were quantified by using Adobe Photoshop, version 5.0 and printed on a Kodak DS 8650 printer (Rochester, NY). A semi-quantitative estimation based on the relative staining intensity of protein expression by the control and transformed cells was determined. This computer program indicates the area and the intensity of the staining of the cells present in the culture dishes. The number of immunoreactive cells was counted in several randomly selected microscopic fields per sample. The experiments were repeated with three similar passages. Standard errors of mean are shown in the different figures. Statistical analysis was performed with the F-test (Randomized Block) and comparisons between groups with the Bonferroni $\mathrm{t}$-test with significance at $\mathrm{P}$ values of $<0.05$.

Isolation and purification of total RNA and mRNA. Total RNA was isolated from both the control (MCF-10F) and treated cell lines with TRIzol reagent (Invitrogen Corp., Long Island, NY). Each sample comprising $500 \mu \mathrm{g}$ of total RNA, was treated with $5 \mu \mathrm{l}$ of DNase I (10 U/ $\mu \mathrm{l})$ (Boehringer Mannheim, Indianapolis, IN) for $60 \mathrm{~min}$ at $37^{\circ} \mathrm{C}$. Then $10 \mathrm{X}$ Termination Mix (0.1 M EDTA, pH 8.0 and $1 \mathrm{mg} / \mathrm{ml}$ glycogen) (Clontech, CA) was used to stop the reaction. Each sample was then purified following established procedure $(12,47)$. The amount of each purified RNA sample was first measured by a spectrophotometer (the ratio of absorbance reading at $260 \mathrm{~nm} / 280 \mathrm{~nm}$ should be $>1.8$ ) and then electrophoresed on denaturing formaldehyde/agarose/ ethidium bromide gel, to check its quality and purity from proteins and

Table I. Differentially expressed genes in atropine- and parathion-treated cells.

\begin{tabular}{|c|c|c|c|c|c|}
\hline Array location & Gene name (symbol) & MCF-10F & Atropine & Parathion & Parathion + Atropine \\
\hline 1 & ABL/JTK7 (ABL1) & - & - & $\uparrow$ & $\uparrow$ \\
\hline 7 & Cyclin A1 (CCNA1) & - & $\uparrow$ & $\uparrow$ & $\uparrow$ \\
\hline 14 & Cyclin D3 (CCND3) & - & - & $\uparrow$ & $\uparrow$ \\
\hline 15 & CCNE (CCNE1) & - & $\uparrow$ & $\uparrow$ & $\uparrow$ \\
\hline 16 & CYCE2 (CCNE2) & - & $\uparrow$ & $\uparrow$ & $\uparrow$ \\
\hline 22 & CDK1 /DKFZp686L20222 (CDC2) & - & $\uparrow$ & $\uparrow$ & $\uparrow$ \\
\hline 23 & p55CDC (CDC20) & - & $\uparrow$ & $\uparrow$ & $\uparrow$ \\
\hline 29 & CDC18L/HsCDC18 (CDC6) & - & - & - & $\uparrow$ \\
\hline 39 & ARF/CDK41(CDKN2A) & - & - & $\uparrow$ & - \\
\hline 63 & BM28/CCNL1 (MCM2) & - & - & $\uparrow$ & - \\
\hline 64 & HCC5/P1-MCM3 (MCM3) & - & - & $\uparrow$ & - \\
\hline 65 & CDC21/CDC54 (MCM4) & - & $\uparrow$ & $\uparrow$ & $\uparrow$ \\
\hline 67 & MCGr40308/Mis 5 & - & $\uparrow$ & $\uparrow$ & $\uparrow$ \\
\hline
\end{tabular}

$\uparrow$ Arrow indicates the up-regulated expression; $\downarrow$ arrow indicates the down-regulated expression; and (-) indicates no change in expression of each gene with respect to control MCF-10F. To note, both the up-regulation and down-regulation of gene expression between 2- and 5-fold alterations were taken into consideration. 
free nucleotides. Each sample of $500 \mu \mathrm{g}$ of purified total RNA was then subjected to polyA ${ }^{+}$RNA analysis with the Oligotex mRNA Purification kit (Qiagen Inc., Valencia, CA). PolyA ${ }^{+}$RNA was then purified following established procedures (47).

cDNA expression array and synthesis of cDNA probes from $m R N A$. GE Array Q Series Human DNA cell cycle cDNA expression array membranes were purchased from SuperArray (Bethesda, MD). They are designed to profile the gene expression of a panel of $190 \mathrm{key}$ genes associated with cell cycle (Table I). The purified mRNAs were used for the synthesis of cDNA probes with Biotin-16-dUTP (Roche Pharm. Indianapolis, IN). Annealing mixture was prepared by mixing $\sim 1.0-5.0 \mu \mathrm{g}$ of mRNA with $3 \mu \mathrm{l}$ of Buffer A (GE primer mix) (SuperArray) and the final volume was adjusted to $10 \mu 1$. The mixture was then incubated in a preheated thermal cycler at $70^{\circ} \mathrm{C}$ for $3 \mathrm{~min}$, cooled to $42^{\circ} \mathrm{C}$ and kept at that temperature for $2 \mathrm{~min}$. Then $10 \mu \mathrm{l}$ of RT cocktail was prepared by mixing $4 \mu 1$ of $5 \mathrm{X}$ Buffer BN [for $50 \mu 110 \mathrm{X}$ Buffer: $1 \mu \mathrm{l}$ of $1 \mathrm{M}$ DTT and $50 \mu \mathrm{l}$ of 10X dNTP mix (5 mM dATP, dCTP, dGTP and $500 \mu \mathrm{M}$ dTTP)], $2 \mu 1$ of Biotin-16UTP, $2 \mu 1$ of RNase-free $\mathrm{H}_{2} \mathrm{O}, 1 \mu \mathrm{l}$ of RNase inhibitor (Promega Corp., Madison, WI) and $1 \mu 1$ of MMLV reverse transcriptase (Promega Corp.). RT cocktail was then warmed at $42^{\circ} \mathrm{C}$ for $1 \mathrm{~min}$ and slowly mixed with $10 \mu \mathrm{l}$ of prewarmed annealing mixture. Then incubation was continued at $42^{\circ} \mathrm{C}$ for $90 \mathrm{~min}$, and then the labeled cDNA probe was denatured by heating at $94^{\circ} \mathrm{C}$ for $5 \mathrm{~min}$, and quickly chilled on ice. In each cell line tested, mRNA was isolated and purified from different passages, and cDNA probes were prepared from each of them and hybridized to the respective membranes. Experiments using the same mRNA preparation were repeated two or three times, and measurable mediannormalized expression values of each gene were compared to avoid false-positive signals (12).

Differential hybridization and chemiluminescent detection of cDNA expression array. Each array membrane was prewetted with $5 \mathrm{ml}$ of de-ionized water and incubated at $60^{\circ} \mathrm{C}$ for $5 \mathrm{~min}$. This was then replaced with $2 \mathrm{ml}$ of prewarmed $\left(60^{\circ} \mathrm{C}\right)$ GEAprehyb solution (GEAhyb solution with a heatdenatured sheared salmon sperm DNA at a final concentration of $100 \mu \mathrm{g} / \mathrm{ml}$ ) (SuperArray) and mixed gently for a few seconds. Prehybridization was continued at $60^{\circ} \mathrm{C}$ for $1-2 \mathrm{~h}$ with continuous gentle agitation. An approximate $0.75-\mathrm{ml}$ solution of GEAhyb was prepared by adding the entire volume of denatured cDNA probe into GEAprehyb solution and kept at $60^{\circ} \mathrm{C}$. Then GEAprehyb solution was replaced by GEAhyb solution and incubation continued overnight with hybridization at $60^{\circ} \mathrm{C}$ with continuous gentle agitation. Subsequently, array membranes were washed twice in wash solution 1 (2X sodium chloride sodium citrate and $1 \%$ sodium dodecyl sulfate) at $60^{\circ} \mathrm{C}$ for 15 min each with gentle agitation and then twice with solution $2(0.1 \mathrm{X}$ sodium chloride sodium citrate and $0.5 \%$ sodium dodecyl sulfate) at $60^{\circ} \mathrm{C}$ for $15 \mathrm{~min}$ each with gentle agitation. GEA blocking solution $(2 \mathrm{ml})$ was added to each membrane and incubated for $40 \mathrm{~min}$ at room temperature with continuous agitation. Then binding buffer was prepared by diluting alkaline phosphatase-conjugated streptavidin (AP) with $1 \mathrm{X}$ buffer $\mathrm{F}$ (SuperArray) in a 1:7500 dilution. GEA blocking solution was replaced by $2 \mathrm{ml}$ of binding buffer and incubated for 10 min with continuous but gentle agitation. Then the membranes were washed 4 times with $4 \mathrm{ml}$ of $1 \mathrm{X}$ binding buffer $\mathrm{F}$ for $5 \mathrm{~min}$ each time and rinsed twice with $3 \mathrm{ml}$ of rinsing buffer $\mathrm{G}$ (SuperArray). After this procedure the membranes were covered with $1.0 \mathrm{ml}$ of CDP-Star chemiluminescent substrate and incubated at room temperature for 2-5 min. They were then exposed to X-ray film (Kodak BioMax MS Film, Kodak Corp.) with a corresponding intensifying screen at room temperature for multiple exposures of 1-5 min. To assess the reproducibility of the hybridization array assays, pair-wise comparisons between array data sets for each cell line were tested by repeated hybridization, and the mRNAs prepared in different lots were analyzed in scatter plots with multiple regression (12).

Quantification of array hybridization. A densitometric scanner (model 300A; Molecular Dynamics, Sunnyvale, CA) was used to quantify the hybridization signals on the expression array membranes after exposure to the autoradiographic film and this was estimated with ImageQuant (Molecular Dynamics) and ScanAnalyze program (Eisen Lab). Volume quantification was performed by calculating the volume under the surface created by a three-dimensional plot of pixel locations and pixel values as described (12). All raw signal intensities were corrected for background by subtracting the signal intensity of a negative control or blank. To delineate the potential signal interference between adjacent strong hybridization signals, equal-sized ellipses were drawn around each signal area (hybridization spots) using software (ImageQuant/ScanAnalyze) and were then separately scanned and compared with housekeeping genes in order to minimize the chances of interference between adjacent strong hybridization signals. Data from only higher concentration spots were used. Median background was subtracted, and signals that were $<2.0$-fold above the background level were considered too low to accurately measure and were omitted from the analysis.

\section{Results}

The spontaneously immortalized human breast epithelial cell line MCF-10F was used in this study. This cell line has a near diploid karyotype and has a luminal epithelial origin. It retains all the characteristics of normal epithelium in vitro, including anchorage independence, non-invasiveness and non-tumorigenicity in nude mice $(13,46)$. Fig. 1A shows the origin and phenotypic characteristics of the cell lines used in this study. These results showed that parathion-treated cells grew as a contact-inhibited monolayer. Fig. 1B shows the invasive characteristics of MCF-10F cells after the various treatments scored at $20 \mathrm{~h}$ after plating onto the matrigel. The immortalized MCF-10F cell line did not show any invasive capability. Addition of parathion to the growth medium significantly $(\mathrm{P}<0.05)$ induced the invasive phenotype of the MCF-10F cells, yet atropine alone and in combination with parathion inhibited this effect. However, these two cell lines had a higher capacity than the control MCF-10F cells. Cell 


\section{A}

Origin and phenotypic characteristics of cell lines

\begin{tabular}{llcc}
\hline Cell lines & Origin & AIA & IA \\
& MCF-10F parental cells & - & - \\
Control & MCF-10F treated with atropine & - & - \\
Atropine (A) & MCF-10F treated with parathion & + & + \\
Parathion (P) & MCF-10F treated with both & - & - \\
Parathion + Atropine (P+A) & -
\end{tabular}

B
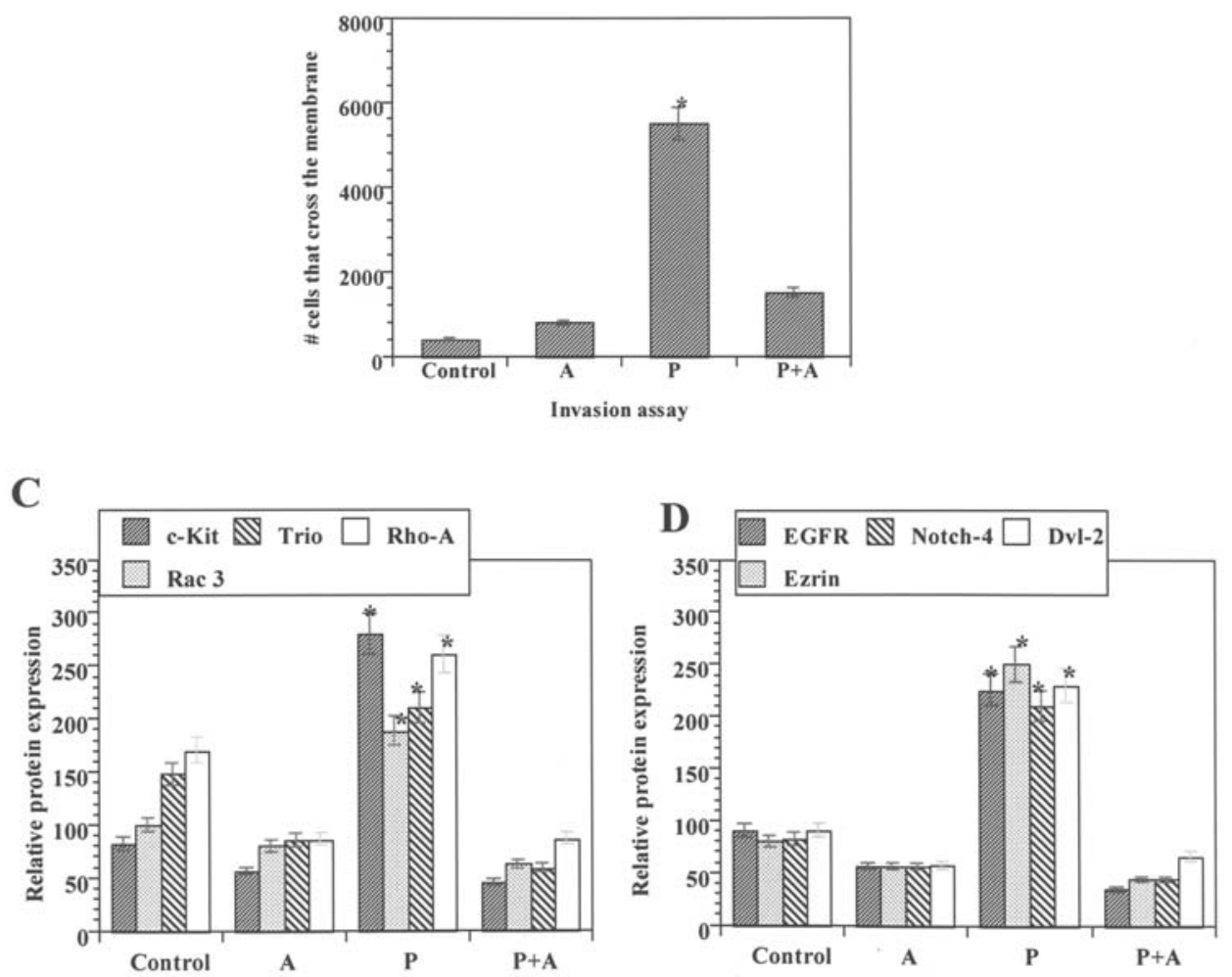

Figure 1. (A) Origin and phenotypic characteristics of the cell lines. AIA, anchorage independence assay; IA, invasion assay. Invasive characteristics of control and treated MCF-10F cells scored $20 \mathrm{~h}$ after plating onto matrigel basement membranes using modified Boyden's chambers constructed with multiwell cell culture plates and cell culture inserts. (+), the results obtained in relation to anchorage-independent growth and number of cells that crossed the filters; (-), lack of anchorage-independent growth and invasiveness. (B) Invasion assay; the average number of cells that crossed the matrigel basement membrane. Bars in the figure indicate mean \pm standard error. ${ }^{*} \mathrm{P}<0.05$ versus MCF-10F and the other experimental groups. (C) Average relative amounts of immunofluorescent staining of the proteins expressed for c-kit, Trio, Rho-A, Rac-3 and (D) EGFR, Notch-4, Dvl-2 and Ezrin in MCF-10F, atropine-, parathion- and parathion plus atropine-treated cells. Bars in the figure indicate mean \pm standard error of the mean. ${ }^{*} \mathrm{P}<0.05$ versus MCF-10F and other groups.

signaling pathways were examined with these cell lines by analyzing c-kit, Trio, Rho-A, Rac 3 (Fig. 1C) and EGFR, Notch-4, Dvl-2, Ezrin (Fig. 1D) protein expression in MCF$10 \mathrm{~F}$, atropine-, parathion- and parathion plus atropine-treated cell lines. Results indicated that parathion significantly $(\mathrm{P}<0.05)$ increased the protein expression relative to controls and the atropine-treated cell line. Immunofluorescent staining of protein quantification by confocal microscopy indicated that atropine decreased the intensity of expression of all of these proteins in the parathion- and parathion plus atropinetreated cells when compared to control. Fig. 2A and B represents the immunofluorescent staining of protein expression by confocal microscopy of c-kit, Trio, Rho-A, Rac 3 and EGFR, Notch-4, Dvl-2 and Ezrin in MCF-10F, atropine-, parathion- and parathion plus atropine-treated cells. The images of protein expression showed that the nuclei of cells treated with parathion were significantly $(\mathrm{P}<0.05)$ more intensively stained than control, atropine- and parathion plus atropine-treated cell nuclei.

The effect of parathion, atropine and parathion plus atropine on cell proliferation was analyzed based on the total number of cells per dish. Fig. 3A shows the effects of several concentrations of parathion on cell proliferation of the MCF$10 \mathrm{~F}$ cell line after 13 days. Parathion treatment induced cell proliferation at $100 \mathrm{ng} / \mathrm{ml}$ after 6 days. Dose-response studies indicated that cell proliferation was inferior to the control MCF-10F cell line at 200, 400 and $800 \mathrm{ng} / \mathrm{ml}$ of parathion after 9 days. Different doses of atropine are shown in Fig. 3B. Atropine significantly $(\mathrm{P}<0.05)$ reduced cell proliferation in comparison to the control MCF-10F cell line at 125 and $250 \mathrm{ng} /$ 
A
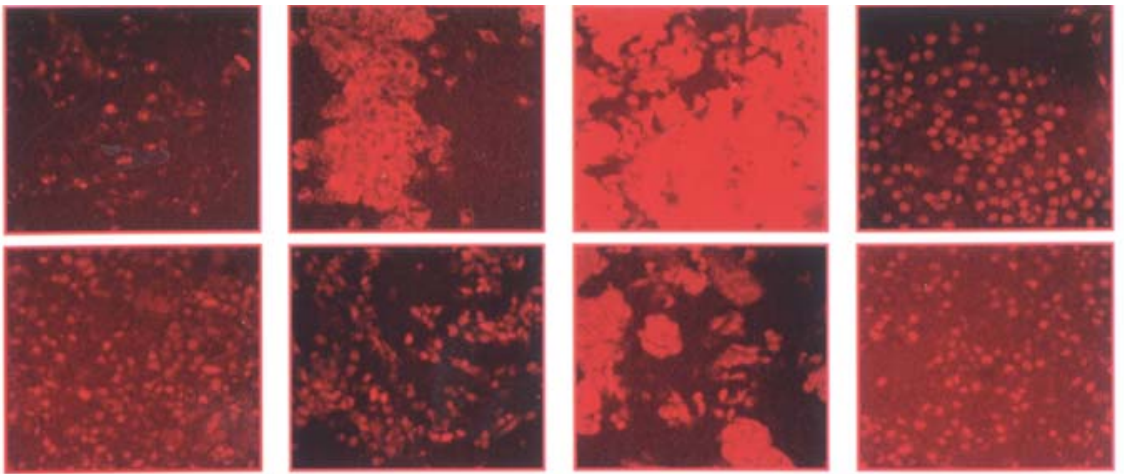

Trio

Rho-A
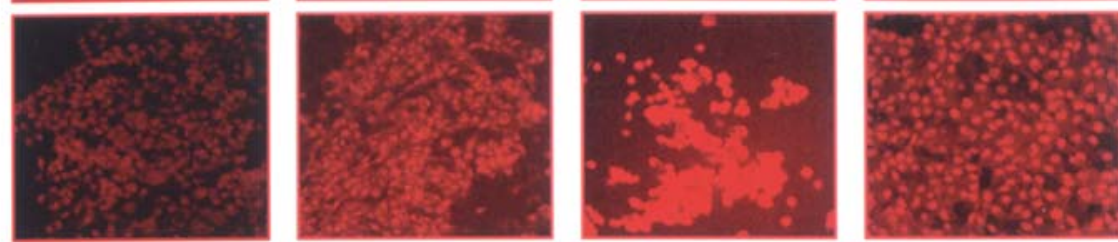

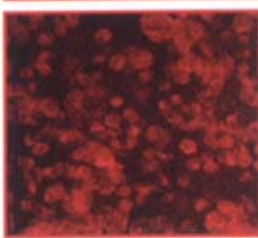

Control

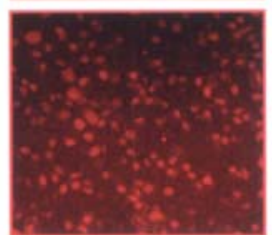

A

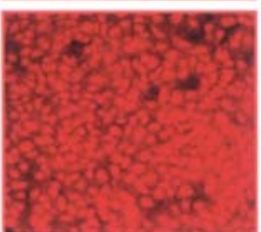

$\mathbf{P}$
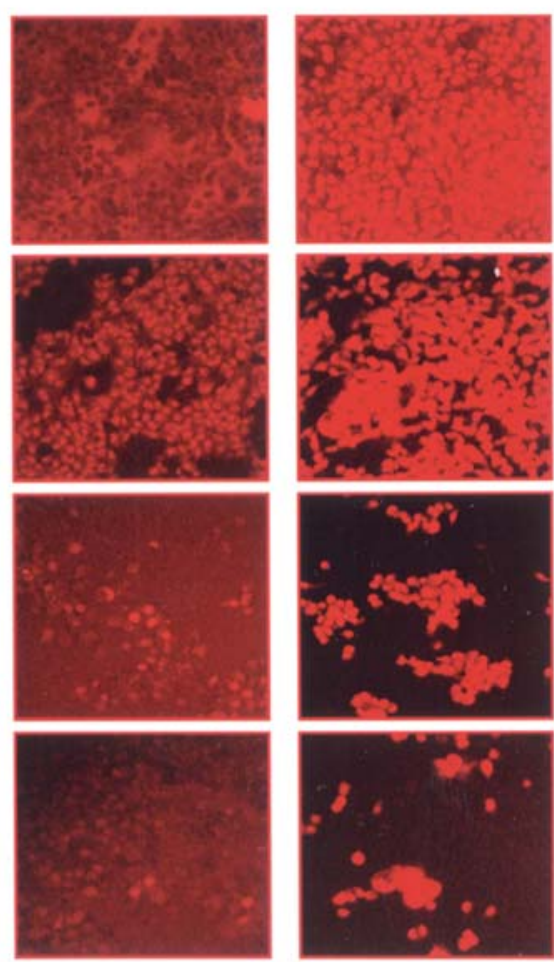

$P$

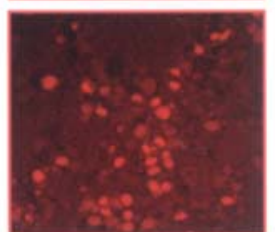

$\mathbf{P}+\mathbf{A}$
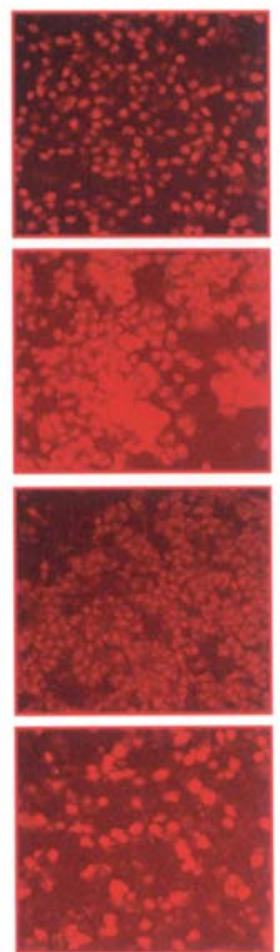

$\mathrm{P}+\mathrm{A}$

Figure 2. Representative fluorescent images of the protein expression of (A) c-kit, Trio, Rho-A, Rac-3 (B) EGFR, Notch-4, Dvl-2 and Ezrin in MCF-10F, atropine (A)-, parathion (P)- and parathion plus atropine $(\mathrm{P}+\mathrm{A})$-treated cell lines by confocal microscopy.

$\mathrm{ml}$ at 9 days. However, $62.5 \mathrm{ng} / \mathrm{ml}$ of atropine was similar to the control for cell proliferation activity. The combined effect of parathion and atropine induced a decrease in cell proliferation in comparison to control and atropine alone (not shown).

Quantification of the immunofluorescent imaging of stained cells showed a significant $(\mathrm{P}<0.05)$ increase in both $\beta$ catenin and mutant p53 protein expression in MCF-10F cells treated with the pesticide compared with the control cultures as seen in Fig. 3C and D. Representative images of immunofluorescent staining of the expression of these two proteins in the MCF-10F, atropine, parathion and parathion plus atropine cell lines are shown in Fig. 3E and F. B catenin protein expression was more intensively stained in the cytoplasm of cells treated with parathion than control, atropine and parathion plus atropine. The staining intensity for mutant $\mathrm{p} 53$ 


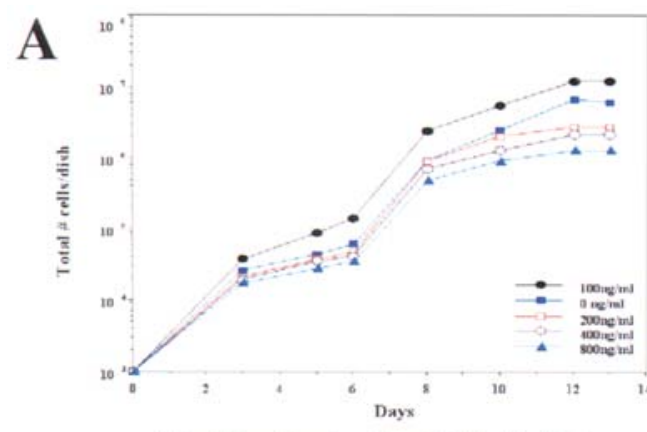

B
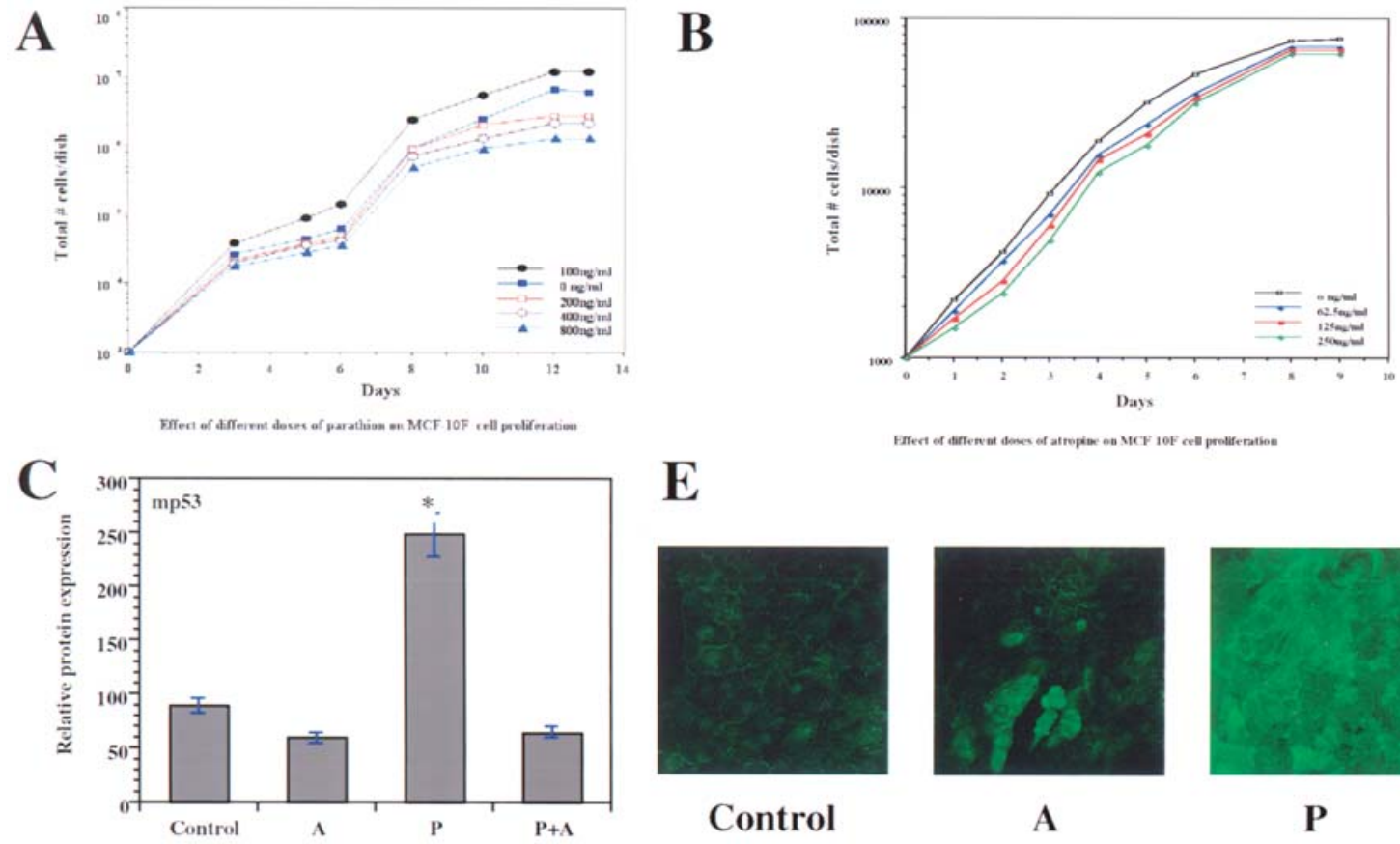

E

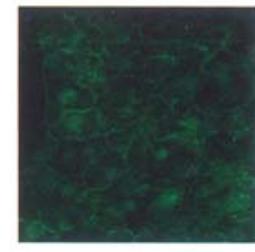

Control

F

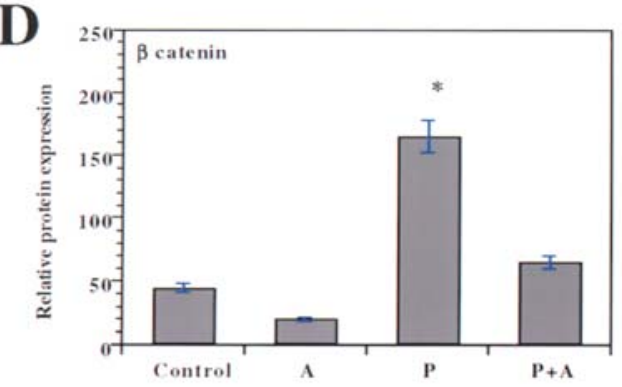

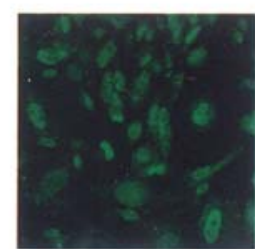

Control

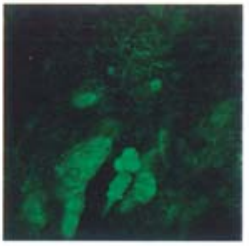

A

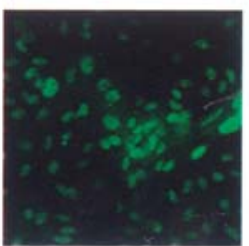

A

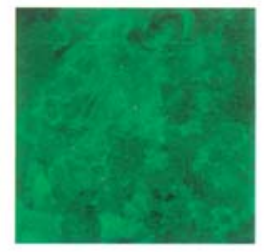

P

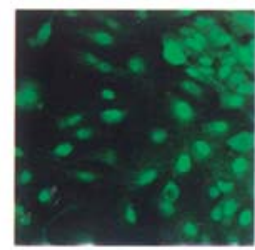

P

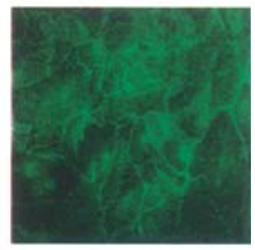

P+A

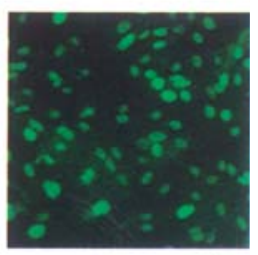

P+A

Figure 3. (A) Cell proliferation studies on the effect of parathion and (B) atropine treatments. The average of relative amounts of immunofluorescent staining of protein expression for $B$ catenin (C) and mutant p53 (D) in MCF-10F, atropine (A)-, parathion (P)- and parathion plus atropine (P+A)-treated cells. Bars in the figure indicate mean \pm standard error of the mean. ${ }^{*} \mathrm{P}<0.05$ versus $\mathrm{MCF}-10 \mathrm{~F}$ and other groups. Representative fluorescent images of $(\mathrm{E}) \mathrm{B}$ catenin and $(\mathrm{F})$ mutant 553 protein expression of MCF-10F, A-, P- and P+A-treated cell lines by confocal microscopy.

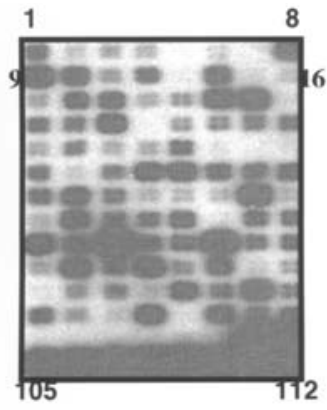

MCF-10F

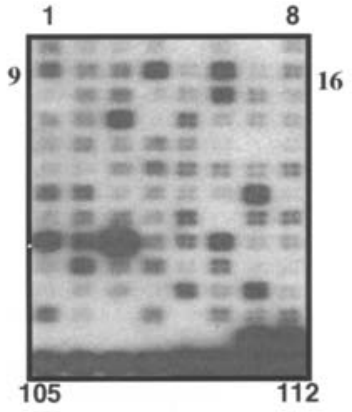

Parathion

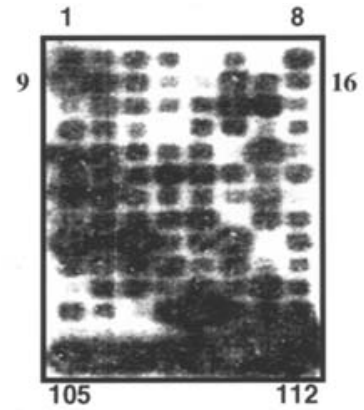

Atropine

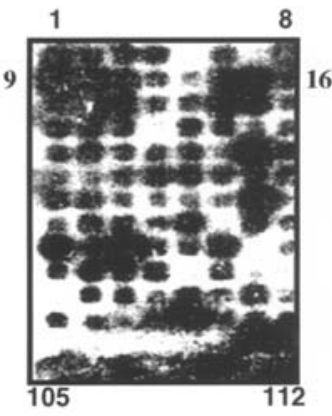

Parathion+Atropine

Figure 4. Differentially expressed genes of human cell cycle cDNA gene array (Q series) of 96 genes analyzed by autoradiography of MCF-10F, parathion-, atropine- and parathion plus atropine-treated cells.

among individual cells was fairly uniform in all the groups. The images of protein expression showed that the nuclei of cells treated with parathion were more intensively stained than control, atropine and parathion plus atropine.

The normal cell line MCF-10F was compared with atropine, parathion and parathion plus atropine to identify differentially expressed genes of human cell cycle arrays after transformation. Results indicated that among the 96 genes, 13 were altered either by parathion, atropine or parathion plus atropine. These genes were related to the $\mathrm{S}$ phase of cell cycle such as the cyclins (A1, A2, C, G1, G2, H) (Fig. 4 and Table I). Among them the genes affected exclusively by parathion were the cyclins, such as cyclin D3, the cyclin-dependent kinases (CDKs) such as CDKN2A and 
the minichromosome maintenance deficient (MCM) MCM2 and MCM3.

\section{Discussion}

It has been previously shown that the organophosphorous pesticide parathion induced rat mammary tumors (8). Here the effect of parathion was evaluated on cell transformation and the protein expression pattern of several markers of signaling pathways in an in vitro model. The effect of this pesticide was analyzed on normal human breast epithelial cell line, MCF-10F. The first observable in vitro signs were morphological changes occurring after the 20th passage posttreatment that represented an early manifestation of transformation. The increase in the rate of cell proliferation indicated by a shorter doubling time, anchorage-independent growth and in vitro invasive capability suggested a very aggressive phenotype. This increased expression of the transformed phenotype among the pesticide-treated cells was consistent with other treatments of this cell line, such us DMBA, BP, high LET radiation $\alpha$ particles $(13,14,44)$ in which the chemoinvasion, or the ability of transformed cells to cross basement membranes in vitro, was correlated with the malignant characteristics of the cells. By using a reconstituted membrane it was shown that the parathiontreated cells exhibited significant invasive capabilities in comparison to the control. However, atropine inhibited such an effect either alone or combined with parathion.

A great deal of progress has been made in understanding the pathogenesis of breast cancer allowing the development of useful tumor markers or signaling molecules of several pathways. It is well known that genetic changes which are relevant to tumor initiation often involve the accumulation of multiple abnormalities in individual cells. We have previously reported the identification of differentially expressed genes by cDNA expression arrays such as the $c$-Kit proto-oncogene, Ezrin (villin 2), Notch-4, EGFR/ERBBI, transforming protein $R h o A$ and $D v l$ genes by high linear energy transfer radiation and estrogen-treated MCF-10F cell lines (12). In these studies the same genes had elevated levels of c-Kit, Ezrin, Notch-4, EGFR/ERBBI, transforming protein Rho-A and Dvl protein expression in the parathion-treated MCF-10F cell line in comparison to control and parathion plus atropinetreated cell lines. Overexpression of the c-Kit protein has been found in breast cancer $(17,18)$. Activation and/or enhanced expression of positive growth factor regulators and cellular oncogenes have been implicated in the progression of breast cancer (27). The levels of EGFR, Notch-4, Dvl-2 and Ezrin protein expression were largely enhanced in the parathiontreated MCF-10F cell line in comparison to control and parathion plus atropine-treated cell lines. EGF probably influenced cell growth through its interaction with a cell surface glycoprotein EGF receptor.

Since it has been reported that c-Ha-ras has a number of effectors that impinge on the neoplastic phenotype, it was interesting to find that Rac as well as Rho-A were overexpressed in the parathion-treated cells. It can be suggested that Rho-A may have a role in the invasive capabilities observed in parathion-treated cells since Rho-A is involved in cell polarity and motility according to other reports. Since
Rac 3 belongs to the Ras superfamily and regulates many fundamental processes in all eukaryotic cells such as growth, vesicle traffic and cytoskeletal organization, parathion may influence such effects. As Rac1 and Rac2 are almost identical and share binding with other members of the Ras family, it is possible that parathion not only altered c-Ha-ras but all of the other related proteins. Kleer et al (49) have analyzed the relevance of Rho proteins in tumor progression by studying protein levels in breast tumors. They found that Rho-A protein expression was higher in all breast tumor samples when compared to normal tissues originating from the same patient. Such an increase was correlated with histological grade and proliferation index in tumor samples. Thus Rho-A protein expression could be a good marker to identify breast cancer patients with a high risk of developing metastases, and it would be a prognostic marker useful in the clinic.

The catenin/cadherin complexes play an important role mediating cellular adhesion (33). The function of the cadherin - catenin system in cell adhesion as well as intracellular signaling appears to be subjected to multifactorial control by a variety of different mechanisms (34). The present study showed that $\beta$ catenin expression was increased in the invasive parathion-treated cell line. However, atropine inhibited the invasive capabilities and acted as an antidote to acetylcholinesterase inhibitors. It can be suggested that parathion altered the catenin complex and induced invasiveness characteristics. It was reported that when malignant transformation of human bronchial epithelial cells was induced with the tobacco-specific nitrosamine, 4-(methylnitrosamino)-1-(3-pyridyl)-1-butatone an overexpression of $\beta$ catenin was observed (50). $\beta$ catenin has been associated with breast cancer progression in vitro (14). Changes in the morphological phenotypes were found in the human breast epithelial MCF-10F cell line transformed by benz $(\alpha)$ pyrene and transfected with $c$-Ha-ras oncogenes with higher $\mathrm{B}$ catenin protein expression. Other authors have found that catenin, especially when it is expressed in the cytoplasm, seems to be a very sensitive prognostic marker with the E-cadherin complex in invasive breast cancer $(33,34)$. The $\beta$ catenin also plays a role in intracellular signaling and functions as an oncogene when it binds to the T-cell factor named Tcf4binding site in the promoter region of cyclin D1 and transactivates genes after translocation to the nucleus (33).

This report is the first demonstration that an organophosphorous pesticide can induce cell transformation in a normal cell line such as MCF-10F which is normally negative for mutant $p 53$ but became positive. Furthermore, atropine inhibited this action. Thus, it can be suggested that a loss of p53 function is possibly responsible for the genetic instability of these transformed cells. It has been previously reported that the overexpression of oncoproteins, such as mutant p53 is an important factor in the process of transformation of human breast epithelial cells induced by several carcinogens such as DMBA, BP as well as high LET radiation in the presence of estrogen $(14,44)$. MCF-10F cell lines exposed to double doses of $\alpha$ particle radiation and treated with estrogen showed a very complex pattern of allelic imbalance. During the process of cell transformation the p53 gene was altered at $17 \mathrm{p} 13.1$ (48). Several studies have shown that the expression of mutant $p 53$ increases as breast cancer 
progresses from early in situ to advanced metastatic lesions $(36,37)$. Post-translational modifications and activation of p53 by genotoxic stresses have been reported (51) indicating that pesticides may influence changes in the $p 53$ gene.

The development of tumor progression appears to involve increase in cell division as well as increase in risks of genetic damage that induce activation and/or changes in the expression of oncogenes and the loss or inactivation of tumor suppressor genes. Thus, tumor cells may have altered genes related to their cell cycle. In summary, results of the present study clearly demonstrated that an organophosphorous pesticide induced phenotypic transformation of an immortalized human breast cell line indicating that these substances may influence carcinogenesis in the human. Thus, parathion was capable of altering cell proliferation and inducing transformation and altered protein expression in an immortalized normal human breast epithelial cell line, whereas a combination of this pesticide with atropine inhibited such effects.

\section{Acknowledgements}

The support given by FONDECYT 1040300 (GMC) and UTA 4714-04 (GMC) are greatly appreciated. We are very grateful to Dr Tom K. Hei for his encouragement and citicism. The secretarial assistance of Danissa Barahona is greatly appreciated. We also thank Mr. Sudhindra R. Swamy for his assistance with the confocal microscopy facilities at Columbia University.

\section{References}

1. Krieger N: Exposure, susceptibility and breast cancer risk: a hypothesis regarding exogenous carcinogens, breast tissue development, and social gradients, including black/white differences, in breast cancer incidence. Breast Cancer Res Treat 13: 205-222, 1989.

2. Davis DL, Axelrod D, Bailey L, Gaynor M and Sasco AJ: Rethinking breast cancer risk and the environment: the case for the precautionary principle. Environ Health Perspect 106: 523-529, 1998.

3. Khayat D, Giroux B, Berille J, Cour V, Gerard B, Sarkany M, Bertrand P and Bizzari JP: Fotemustine in the treatment of brain primary tumors and metastases. Cancer Invest 12: 414-420, 1994.

4. Patel SV: Pharmacotherapy of cognitive impairment in Alzheimer's disease: a review. J Geriatr Psychiatry Neurol 8: 81-95, 1995.

5. Meinking TL, Entzel P, Villar ME, Vicaria M, Lemard GA and Porcelain SL: Comparative efficacy of treatments for pediculosis capitis infestations: update 2000. Arch Dematol 137: 287-292, 2001.

6. Klaasen C: Nonmetallic environmental toxicants: air pollutants, solvents and vapors, and pesticides. In: The Pharmacological Basis of Therapeutics. Goodman Gilman A, Rall TW, Nies AS and Taylor P (eds). Pergamon Press Inc, New York, pp1615-1635, 1990.

7. Taylor P: The cholinesterase. J Biol Chem 266: 4025-4028, 1991.

8. Cabello G, Valenzuela M, Vilaxa A, Durán V, Rudolph I, Hrepic N and Calaf G: A rat mammary tumor model induced by the organophosphorous pesticides, parathion and malathion, possibly through acetylcholinesterase inhibition. Environ Health Perspect 109: 471-479, 2001.

9. Loeb LA: Mutator phenotype may be required for multistage carcinogenesis. Cancer Res 51: 3075-3079, 1991.

10. Knudson AG: Hereditary cancer, oncogenes and antioncogenes. Cancer Res 45: 1437-1443, 1985.

11. Schwab M, Varmus HE and Bishop JM: Amplification of cellular oncogenes in tumor cells. In: Cancer Cells. Vande Woude GF (ed). Cold Spring Harbor Laboratory Press, Cold Spring Harbor, NY, pp215-220, 1984.
12. Roy D, Calaf G and Hei TK: Profiling of differentially expressed genes induced by high linear energy transfer radiation in breast epithelial cells. Mol Carcinog 31: 192-203, 2001.

13. Calaf $G$ and Hei TK: Establishment of a radiation- and estrogen-induced breast cancer. Carcinogenesis 21: 769-776, 2000.

14. Calaf G, Alvarado M and Hei TK: Beta catenin is associated with breast cancer progression in vitro. Int J Oncol 26: 913-921, 2005.

15. Calaf G, Roy D and Hei TK: Immunochemical analysis of protein in breast epithelial cells transformed by estrogens and high linear energy transfer (LET) radiation. Histochem Cell Biol 124: 261-274, 2005.

16. Calaf G, Alvarado ME and Hei TK: Oncoprotein expression and morphological phenotypes of human breast epithelial cell transformed by $c$-Ha-ras oncogene. Oncol Rep 14: 885-893, 2005.

17. Hines SJ, Litz JS and Krystal GW: Coexpression of c-kit and stem cell factor in breast cancer results in enhanced sensitivity to members of the EGF family of growth factors. Breast Cancer Res Treat 58: 1-10, 1999.

18. Ko CD, Kim JS, Ko BG, Son BH, Kang HJ, Yoon HS, Cho EY, Gong $\mathrm{G}$ and Ahn SH: The meaning of the c-kit proto-oncogene product in malignant transformation in human mammary epithelium. Clin Exp Metastasis 20: 593-597, 2003.

19. Debant A, Serra-Pages C, Seipel K, O'Brien S, Tang M, Park SH and Streuli M: The multi-domain protein Trio binds the LAR transmembrane tyrosine phosphatase, contains a protein kinase domain, and has separate Rac-specific and Rho-specific guanine nucleotide exchange factor domains. Proc Natl Acad Sci USA: 93: 5466-5471, 1996.

20. Elson A and Leder P: Protein tyrosine phosphatase $\varepsilon$. An isoform specifically expressed in mouse mammary tumors initiated by v-Ha-Ras. J Biol Chem 270: 26116-26122, 1995.

21. Olofsson B, Chardin P, Touchot N, Zahraoui A and Tavitian A: Expression of the ras-related ral A, rho 12 and rab genes in adult mouse tissues. Oncogene 3: 231-234, 1985.

22. Yeramian P, Chardin P, Madaule P and Tavitian A: Nucleotide sequence of human rho cDNA clone 12. Nucleic Acids Res 15: $1869,1987$.

23. Garrett MD, Self AJ, Van Oers C and Hall A: Identification of distinct cytoplasmic targets for ras/R-ras and rho regulatory proteins. J Biol Chem 264: 10-13, 1989.

24. Lui VW and Grandis JR: EGFR-mediated cell cycle regulation. Anticancer Res 22: 1-11, 2002.

25. Rubin I and Yarden Y: The basic biology of HER2. Ann Oncol 12: S3-S8, 2001

26. Yamamoto T, Ikawa S, Akiyama T, Semba K, Nomura N, Miyajima N, Saito T and Toyoshima K: Similarity of protein encoded by the human $c$-erb- $B-2$ gene to epidermal growth factor receptor. Nature 319: 230-234, 1986.

27. Kraus MH, Issing W, Miki T, Popescu NC and Aaronson SA: Isolation and characterization of ERBB3, a third member of the $\mathrm{ERBB} /$ epidermal growth factor receptor family: evidence for overexpression in a subset of human mammary tumors. Proc Nat Acad Sci USA 86: 9193-9197, 1989.

28. Kopan R and Weintraub H: Mouse notch: expression in hair follicles correlates with cell fate determination. J Cell Biol 121: 631-641, 1993.

29. Miele L, Miao H and Nickoloff BJ: NOTCH signaling as a novel cancer therapeutic target. Curr Cancer Drug Targets 4: 313-323, 2006.

30. Wagner U, Brownlees J, Irving NG, Lucas FR, Salinas PC and Miller CC: Overexpression of the mouse dishevelled-1 protein inhibits GSK-3ß mediated phosphorylation of tau transfected mammalian cells. FEBS Lett 411: 369-372, 1997.

31. Gould KL, Bretscher A, Esch FS and Hunter T: cDNA cloning and sequencing of the protein-tyrosine kinase substrate, Ezrin, reveals homology to band 4.1. EMBO J 8: 4133-4142, 1989.

32. Algrain M, Turunen O, Vaheri A, Louvard D and Arpin M: Ezrin contains cytoskeleton and membrane binding domains accounting for its proposed role as a membrane-cytoskeletal linker. J Cell Biol 120: 129-139, 1993.

33. Takayama T, Shiozaki H, Shibamoto S, Oka H, Kimura Y, Tamura S, Inoue M, Monden T, Ito F and Monden M: Beta-catenin expression in human cancers. Am J Pathol 148: 39-46, 1996.

34. Breen E, Steele G Jr and Mercurio AM: Role of the E-cadherin/ alpha-catenin complex in modulating cell-cell and cell-matrix adhesive properties of invasive colon carcinoma cells. Ann Surg Oncol 2: 378-385, 1995. 
35. Levine AJ, Momand J and Finlay CA: The p53 tumor suppressor gene. Nature 351: 453-456, 1991.

36. Callahan R: p53 mutations, another breast cancer prognostic factor. J Natl Cancer Inst 84: 826-827, 1992.

37. Nigro JM, Baker SJ, Preisinger AC, Jessup JM, Hostetter R, Cleary K, Bigner SH, Davidson N, Baylin S, Devilee P, et al: Mutations in p53 gene occur in diverse human tumor types. Nature 342: 705-708, 1989.

38. Nurse P: A long twentieth century of the cell cycle and beyond. Cell 100: 71-80, 2000.

39. Deshaies RJ: The self-destructive personality of a cell cycle in transition. Curr Opin Cell Biol 7: 781-789, 1995.

40. Gardner RD and Burke DJ: The spindle checkpoint: two transitions, two pathways. Trends Cell Biol 10: 154-158, 2000

41. Dasika GK, Lin SC, Zhao S, Sung P, Tomkinson A and Lee EY: DNA damage-induced cell cycle checkpoints and DNA strand break repair in development and tumorigenesis. Oncogene 18: 7883-7899, 1999.

42. Bottazzi ME and Assoian RK: The extracellular matrix and mitogenic growth factors control G1 phase cyclins and cyclindependent kinase inhibitors. Trends Cell Biol 7: 348-352, 1997.

43. Soule HD, Maloney TM, Wolman SR, Peterson WD Jr, Brenz R, McGrath CM, Russo J, Pauley RJ, Jones RF and Brooks SC: Isolation and characterization of a spontaneously immortalized human breast epithelial cell line, MCF-10. Cancer Res 50: 6075-6086, 1990.
44. Calaf G and Hei TK: Oncoprotein expressions in human breast epithelial cells transformed by high-LET radiation. Int J Radiat Biol 77: 31-40, 2001

45. Calaf G, Russo J and Alvarado ME: Morphological phenotypes in neoplastic progression of benz (alpha) pyrene-treated breast epithelial cells. J Submicrosc Cytol Pathol 32: 535-545, 2000.

46. Calaf $\mathrm{G}$ and Russo J: Transformation of human breast epithelial cells by chemical carcinogens. Carcinogenesis 14: 483-492, 1993.

47. Sambrook J, Fritsch EF and Maniatis T: Molecular Cloning. A Laboratory Manual. Cold Spring Harbor Laboratory Press, Cold Spring Harbor, NY, 1989.

48. Roy D, Calaf G and Hei TK: Frequent allelic imbalance on chromosome 6 and 17 correlate with radiation-induced neoplastic transformation of human breast epithelial cells. Carcinogenesis 22: 1685-1692, 2001.

49. Kleer CG, Van Golen KL, Zhang Y, Wu ZF, Rubin MA and Merajver SD: Characterization of Rho $\mathrm{C}$ expression in benign and malignant breast disease: a potential new marker for small breast carcinomas with metastatic ability. Am J Pathol 160: 579-584, 2002.

50. Zhou H, Calaf $\mathrm{G}$ and Hei TK: Malignant transformation of human bronchial epithelial cells with the tobacco-specific nitrosamine, 4-(methylnitrosamino)-1-(3-pyridyl)-1-butatone. Int J Cancer 106: 821-826, 2003.

51. Appella E and Anderson CW: Post-translational modifications and activation of $\mathrm{p} 53$ by genotoxic stresses. Eur J Biochem 268: 2764-2772, 2001. 